\title{
KEUNGGULAN ASBUTON PRACAMPURAN DAN ASPAL SHELL PADA CAMPURAN ASPAL BETON (AC-BC)
}

\author{
Sumiati $^{1}$, Mahmuda $^{2}$, Puryanto ${ }^{3}$ \\ 1,2,3 Jurusan Teknik Sipil, Politeknik Negeri Sriwijaya, Jl.Srijaya Negara Bukit Besar Plg, 30139 \\ Email: ${ }^{1}$ sumiati@polsri.ac.id
}

\begin{abstract}
The current national asphalt needs for road infrastructure development reaches 1.6 million tons /year. Pertamina production can only meet about $30 \%$, the rest of $70 \%$ imported from Singapore. Meanwhile, the raw material reserves in Buton Island, if extracted can supply the national road needs \pm 360 years. In order to increase the utilization of domestic natural potential and wealth and reduce the import of oil asphalt The government requires national road projects to use asbuton pre-blended, but this is not maximally applied in the field. The reason is still more expensive pre-blended asbuton prices that have not been mass produced and the public is usually more confident with branded abroad. Whereas asbuton pre-blended has higher nitrogen compounds and lower paraffin compounds than oil asphalt, so it is possible that asbuton pre-blended has better adhesion. Based on the above problems, we will examine the effect of using asbuton pre-blended and asphalt oil of Pertamina (Ex Shell PEN 60/70) on concrete asphalt pavement layer (AC-BC) to Marshall characteristic value. Marshal tests were performed on 90 specimens using aggregates taken from three locations with different abrasion values. To obtain optimum bitumen content (KAO), binder used asbuton preblended and oil asphalt as comparison.The results showed that by using asbuton pre-blended to save the use of asphalt and the value of Marshall Characteristic fulfill the specification of pavement asphalt layer (Bina Marga revision 3, 2010) and Guidelines of Asphalt Mixture Technical Specification with Ministry of Public Works (2013).
\end{abstract}

Key words : Asbuton preblended, shell asphalt, Marshall characteristic

\begin{abstract}
ABSTRAK
Kebutuhan aspal nasional saat ini untuk pembangunan infrastruktur jalan mencapai 1,6 juta ton/tahun. Produksi pertamina hanya dapat memenuhi sekitar 30\%, sisanya sebanyak $70 \%$ diimpor dari Singapura. Sementara itu cadangan bahan baku di Pulau Buton, bila diesktraksi dapat menyuplai kebutuhan jalan nasional \pm 360 tahun. Dalam rangka meningkatkan pemanfaatan potensi dan kekayaan alam dalam negeri dan mengurangi impor aspal minyak Pemerintah mewajibkan proyekproyek jalan nasional menggunakan asbuton pracampuran, namun hal ini tidak maksimal diterapkan di lapangan. Penyebabnya adalah masih lebih mahalnya harga asbuton pracampuran yang belum diproduksi secara massal dan masyarakat biasanya lebih percaya dengan branded luar negeri. Padahal asbuton pracampuran memiliki senyawa nitrogen yang lebih tinggi dan senyawa parafin yang lebih rendah dibandingkan aspal minyak, sehingga dimungkinkan asbuton pracampuran mempunyai daya rekat lebih baik. Berdasarkan permasalahan di atas maka akan diteliti pengaruh penggunaan asbuton pracampuran dan aspal minyak pertamina (Ex Shell PEN 60/70) pada lapis perkerasan aspal beton (AC-BC) terhadap nilai karakteristik Marshall. Pengujian Marshal dilakukan terhadap 90 benda uji dengan mengggunakan agregat yang diambil dari tiga lokasi dengan nilai abrasi yang berbeda. Untuk mendapatkan kadar aspal optimum (KAO), bahan pengikatyang digunakan asbuton pracampuran dan aspal minyak sebagai pembandingnya. Hasil penelitian didapatkan bahwa dengan menggunakan asbuton pracampuran dapat menghemat penggunaan aspal dan nilai karaktiristik Marshall memenuhi persyaratan Spesifikasi Lapis Perkerasan Aspal (Bina Marga revisi 3, 2010) dan Pedoman Spesifikasi Teknis Campuran Beraspal dengan Asbuton (Kementerian Pekerjaan Umum, 2013).
\end{abstract}

Kata kunci : Asbuton pracampuran, aspal shell, karakteristik Marshall 


\section{PENDAHULUAN}

Asbuton ditemukan tahun 1924 di Pulau Buton, Sulawesi Tenggara. Asbuton mulai digunakan dalam pengaspalan jalan sejak tahun 1926. Berdasarkan data yang ada, asbuton memiliki deposit sekitar 677 juta ton atau setara dengan 170 juta ton aspal minyak yang merupakan deposit aspal alam terbesar di dunia.

Kebutuhan aspal nasional saat ini untuk pembangunan infrastruktur jalan mencapai 1,6 juta ton/tahun. Produksi pertamina hanya dapat memenuhi sekitar 30\%, sisanya sebanyak 70\% diimpor dari Singapura.

Selama ini penggunaan asbuton yang telah diproduksi secara fabrikasi dan manual selama bertahun-tahun berupa Asbuton Butir dan Asbuton Murni Full Ekstraksi masih belum optimal, hal ini dikarenakan masih sulitnya proses pencampuran di AMP (Asphalt Mixing Plant), sehingga tidak didapatkannya hasil yang maksimal. Beberapa tahun belakangan ini telah diproduksi Asbuton Pracampuran (preblended), merupakan gabungan antara Asbuton butir hasil refine Asbuton dengan kadar bitumen 60\% sampai 90\% dengan aspal minyak pen 60 dalam komposisi tertentu. Asbuton jenis ini dapat dikatakan sebagai aspal minyak yang dimodifikasi, sehingga dalam campuran dapat langsung digunakan untuk dicampur dengan agregat.

Berdasarkan hasil penelitian skala laboratorium dan skala uji coba lapangan, diperoleh fakta bahwa campuran beraspal yang menggunakan Asbuton memiliki sifat teknik yang baik daripada campuran tanpa Asbuton, seperti: Stabilitas Marshall dan dinamis, kelenturan serta daya lekat yang lebih tinggi, dapat meningkatkan umur konstruksi (dari hasil uji fatigue) dan lebih tahan terhadap perubahan temperatur. Namun, untuk setiap tipe campuran sebaiknya dibedakan peruntukannya sesuai dengan kondisi lalu lintas dan lingkungan (Nala Anggada Perkasa, 2014). Asbuton pracampuran memiliki senyawa nitrogen yang lebih tinggi dan senyawa paraffin yang lebih rendah dibandingkan aspal minyak, sehingga dimungkinkan asbuton pracampuran mempunyai daya rekat lebih baik.

Anwar Yamin, dkk, 2014, mengevaluasi asbuton pracampuran di lapangan yang telah memiliki umur pelayanan tertentu, didapatkan bahwa; asbuton pracampuran memiliki ketahanan terhadap rutting yang baik, tetapi ketahanan terhadap retak yang lebih rendah dibandingkan aspal PEN 60.

Nyoman, 2016, melakukan penelitian Campuran beraspal hangat menggunakan Asbuton pracampuran menunjukkan karakteristik yang baik dan memenuhi ketentuan spesifikasi yang ditentukan. Sedangkan jika ditambahkan bahan tambah Leadcap sebanyak $1 \%$, mempunyai ketahanan terhadap alur, ketahanan terhadap air dan nilai modulus resilien meningkat serta ketahanan terhadap pelepasan butir yang lebih baik. Sementara itu ketahanan terhadap retak lelahnya lebih rendah.

Penelitian Bayu (2017) pada Campuran Hot Rolled Asphalt (HRA), didapatkan hasil bahwa: Stabilitas HRA Retona memiliki persentase penurunan lebih kecil dibanding HRA Pen 60/70 setelah terendam air laut 192 jam. Nilai flow HRA Pen 60/70 memiliki nilai lebih tinggi dibanding dengan HRA Retona pada setiap variasi durasi rendaman air laut. HRA Retona lebih kedap air dibandingkan HRA Pen 60/70. Nilai IRS(Index of Retained Stability) HRA 
Retona lebih baik pada setiap durasi rendaman air laut dibanding HRA Pen $60 / 70$. Setelah durasi rendaman air laut 192 jam, nilai ITS (Indirect Tensile Strength) HRA Retona menurun lebih tajam dibanding HRA Pen 60/70, namun pada setiap kondisi nilai ITS campuran HRA Retona lebih tinggi dari HRA Pen 60/70.

Hasil pengujian sifat reologi mekanistik aspal modifikasi Asbuton dan Asphalt Rubber (AR) adalah bahwa kedua aspal modifikasi tersebut menghasilkan nilai Performance Grade (PG) yang lebih baik. Selanjutnya dari analisis terhadap kriteria kerusakan perkerasan, disimpulkan bahwa Asphalt Rubber (AR) memiliki ketahanan lebih baik terhadap deformasi permanen maupun terhadap retak lelah, sedangkan aspal modifikasi Asbuton pada aspal minyak Pen 60/70 akan meningkatkan ketahanan terhadap deformasi permanen, tetapi mengurangi ketahanan terhadap retak lelah (Eva, 2017).

Penelitian-penelitian campuran aspal beton menggunakan Asbuton Murni Full Ekstraksi dan Asbuton Pracampuran telah banyak dilakukan walaupun mempunyai kekurangan dan keunggulan dibandingkan dengan aspal minyak PEN 60/70. Asbuton Pracampuran (preblended)/aspal minyak yang dimodifikasi asbuton mempunyai kemudahan dalam pengerjaan dan sifat-sifat yang lebih baik dari aspal minyak. Namun hal ini belum sepenuhnya menarik perhatian para konsumen disebabkan masih lebih mahalnya harga Asbuton Pracampuran dibandingkan aspal minyak Pertamina. Oleh sebab itu akan diteliti keunggulan asbuton pracampuran dibandingkan dengan aspal Shell Pertamina PEN 60/70 pada campuran aspal beton (ACBC), berdasarkan nilai karakteristik Marshallnya agar didapatkan campuran aspal yang ekonomis dan memenuhi
Spesifikasi Lapis Perkerasan Aspal (Bina Marga revisi 3, 2010) dan Pedoman Spesifikasi Teknis Campuran Beraspal dengan Asbuton (Kementerian Pekerjaan Umum, 2013). Sehingga potensi dan kekayaan alam dalam negeri yang selama ini belum termanfaatkan secara maksimal dapat meningkat dan akan mengurangi impor aspal minyak.

\section{METODE PENELITIAN}

Metode penelitian berupa metode experimental dan akan dilaksanakan di laboratorium Pengujian Bahan Teknik Sipil Politeknik Negeri Sriwijaya. Adapun bahan-bahan yang dibutuhkan dalam penelitian ini adalah: agregat yang diambil dari 3 lokasi ( Lahat, Linggau dan Merak) dengan nilai abrasi yang berbeda. Bahan pengikat berupa Asbuton Pracampuran dari PT. Nala Anggada Perkasa dan Aspal pen 60/70 produksi PT. Pertamina dengan merk Shell.

Agregat yang akan digunakan harus diuji terlebih dahulu untuk mengetahui sifat fisiknya apakah memenuhi persyaratan seperti: Analisa Saringan (SNI 03-1968-1990), berat jenis agregat kasar (SNI 03-1969-1990), berat jenis agregat halus (SNI 03-1970-1990), Butiran Pecah pada agregat kasar (SNI 7619:2012), Gumpalan lempung \& Butiran pecah agregat halus (SNI 034141: 1996), Partikel Pipih dan Lonjong (ASTM D4791 Perbandingan 1:5), Abrasi Los Angeles (SNI 2417:2008), Kelekatan Agregat terhadap aspal (SNI 2439:2011) dan Material lolos ayakan No.200 (SNI 03-4142-1996). Filler diuji berat jenisnya (SNI 03-19701990).

Untuk mendapatkan kadar aspal optimum dibuat benda uji Marshall berbentuk silinder dengan diameter 10 $\mathrm{cm}$ dan tinggi $\pm 7 \mathrm{~cm}$, berat \pm 1200 
gram sebanyak 15 sample, dengan variasi aspal 4,5\%; 5\%; 5,5\%; $6 \%$ dan $6,5 \%$ terhadap berat benda uji. Nilai karakterisik Marshall akan dihitung menggunakan rumus-rumus yang terkait, hasil perhitungan kemudian akan dianalisa dengan menggunakan metode regresi ditampilkan dalam histogram serta berpedoman pada Spesifikasi Umum Divisi VI Revisi 3, 2010 dan Pedoman Spesifikasi Teknis Campuran Beraspal dengan Asbuton, 2013, sehingga akan didapatkan simpulan dari penelitian ini.

\section{HASIL dan PEMBAHASAN}

Metode dan hasil pengujian sifat fisik aspal didapatkan data seperti tertera pada Tabel 1, dapat dilihat bahwa nilai daktilitas, titik lembek, berat jenis aspal, titik nyala dan titik bakar memenuhi persyaratan PEN 60-70 dan Asbuton pracampuran. Nilai penetrasi Asbuton pracampuran lebih rendah dibandingkan dengan Aspal PEN 60-70. Sedangkan suhu pada titik lembek, titik nyala dan titik bakar Asbuton pracampuran lebih tinggi dibandingkan dengan Aspal PEN 60-70, tapi hal ini tidak berbeda secara signifikan.

Metode dan hasil pengujian sifat fisik agregat Kasar dan halus yang diambil dari 3 lokasi dapat dilihat pada Tabel 2 untuk agregat kasar dan Tabel 3 untuk agregat halus, memenuhi persyaratan spesifikasi dan dapat digunakan untuk LASTON (AC-BC). Agregat kasar mempunyai nilai abrasi yang berbeda antara agregat ex Lahat, ex Linggau dan ex Merak yaitu berurutan sebesar: $12,67 \%$; 23,89\% dan 33,44\%, hal ini menunjukkan bahwa agregat mempunyai mutu dan kekerasan yang berbeda-beda yang akan berpengaruh terhadap stabilitas Laston AC-BC.

Benda uji Marshall dibuat dengan menggunakan agregat kasar dan agregat halus dengan komposisi tertentu dan memenuhi gradasi agregat berdasarkan spesifikasi LASTON AC-BC (Gambar 1).

Hasil pengujian nilai karakteristik Marshall, seperti: VIM, VMA, VFA, Stabilitas, pelelehan/flow (Tabel 4) antara AsButon preblended dan aspal PEN 60/70, memenuhi spesifikasi dan tidak berbeda secara signifikan.

Kadar aspal optimum (KAO) Laston AsButon pracampuran dengan menggunakan agregat ex Lahat, ex Linggau dan ex Merak berurutan: 5,1\%; $5,4 \%$ dan 5,8\%, sedangkan jika menggunakan Aspal PEN 60/70 berurutan: $5,4 \%$; 5,6\% dan 6,0\%. Jadi penggunaan AsButon pracampuran dapat lebih sedikit berkisar antara 0,20,3\% dibandingkan dengan Aspal PEN 60/70. Hal ini mendukung hasil penelitian-penelitian: Affandy (2012), bahwa dalam Asbuton Kabungka dan Asbuton Lawele sebagian besar mengandung mineral Kalsium karbonat $\left(\mathrm{CaCO}_{3}\right)$ berkisar $\pm 70-90 \%$ dan silikat $\left(\mathrm{SiO}_{2}\right)$ berkisar \pm 6-15\%, di mana mineral-mineral tersebut dapat mengisi pori-pori antar butiran serta meningkatkan daya ikat antar butiran sehingga dapat mengurangi pemakaian aspal. Penelitian Andri, 2015, dengan menggunakan kapur $\left(\mathrm{CaCO}_{3}\right)$ sebagai filler sebanyak 25\% dan 50\% dapat meningkatkan nilai stabilitas dan durabilitas dari campuran aspal beton. Penelitian Yacob (2017), dengan menggunakan filler abu batu kapur sebanyak 25\% dan Abu Tempurung Kelapa sebanyak $75 \%$ dapat meningkatkan nilai durabilitas pada campuran aspal beton AC-BC.

Pada Gambar 2, dapat diuraikan bahwa: dengan menggunakan agregat ex Lahat dan AsButon Pracampuran dengan KAO 5,1\% didapatkan nilai VIM sebesar 4,7\% sedangkan dengan KAO 
5,4\% nilai VIM turun menjadi 4,2\%. Laston menggunakan aspal PEN 60/70 didapatkan KAO 5,4\% nilai VIM adalah sebesar 4,0\%. Laston menggunakan agregat ex Linggau dan AsButon Pracampuran didapatkan KAO 5,4\% nilai VIM sebesar 4,8\% sedangkan dengan KAO 5,4\% nilai VIM turun menjadi 4,6\%.

Pada Laston menggunakan aspal PEN 60/70 didapatkan KAO 5,6\% nilai VIM adalah sebesar 4,8\%. Laston menggunakan agregat ex Merak dan AsButon Pracampuran didapatkan KAO 5,8\% nilai VIM sebesar 4,8\% sedangkan dengan KAO 6,0\% nilai VIM turun menjadi 4,5\%. Laston aspal PEN 60/70 didapatkan KAO 6,0\% nilai VIM adalah sebesar 4,8\%, namun perbedaan nilai VIM dengan KAO masing-masing campuran tidak berbeda secara signifikan dan masih memenuhi persyaratan spesifikasi.

Void in Mineral Agregat (VMA) yaitu rongga udara yang ada diantara partikel campuran agregat aspal yang sudah dipadatkan termasuk ruang yang terisi aspal yang dinyatakan dalam persen terhadap total volume campuran agregat aspal. Nilai VMA yang diharapkan dalam campuran beraspal yaitu seminimum mungkin, dengan tujuan untuk memberikan ruang yang cukup pada aspal agar dapat melekat pada agregat. Pada Gambar 3, terlihat bahwa Laston AsButon Pracampuran dengan KAO lebih rendah dari Laston aspal PEN 60/70 pada masing-masing campuran memberikan nilai yang minimum.

Void Filled With Asphalt (VFA) menunjukkan presentase besarnya rongga yang dapat terisi oleh aspal. Nilai VFA yang semakin tinggi berarti semakin banyak rongga dalam campuran yang terisi aspal sehingga kekedapan campuran terhadap air dan udara juga semakin tinggi, tetapi nilai VFA yang terlalu tinggi akan menyebabkan bleeding.

Nilai VFA yang terlalu kecil akan menyebabkan campuran kurang kedap terhadap air dan udara karena lapisan film aspal akan menjadi tipis dan akan mudah retak bila menerima penambahan beban sehingga campuran aspal mudah teroksidasi yang akhirnya menyebabkan lapis perkerasan tidak tahan lama.

Pada Gambar 4, batasan berdasarkan spesifikasi nilai VFA untuk Laston AsButon Pracampuran yaitu min 63\%, sedangkan Laston aspal PEN 60/70 VIM min 65\%. Nilai VFA Laston AsButon Pracampuran dengan KAO masing-masing campuran mempunyai nilai yang lebih rendah dibandingkan Laston aspal PEN 60/70. Hal ini mendukung penelitian Gumay, 2014, bahwa: nilai VIM dan VMA campuran beton aspal AC-WC menggunakan Asbuton Retona cenderung lebih tinggi serta nilai VFA lebih rendah dibandingkan dengan Aspal Pertamina PEN 60/70. Asbuton Retona dapat digunakan sebagai bahan ikat campuran AC-WC, karena terbukti pada kadar aspal optimum memenuhi spesifikasi karakteristik beton aspal AC-WC.

Stabilitas merupakan kemampuan lapisan untuk menahan deformasi akibat beban lalu lintas yang bekerja diatasnya tanpa mengalami perubahan bentuk, seperti gelombang (wash boarding) dan alur (rutting). Nilai stabilitas dipengaruhi oleh bentuk, kualitas, tekstur permukaan dan gradasi agregat, yaitu gesekan antar butiran agregat (internal friction) dan penguncian antar agregat (interlocking), daya lekat (cohesion) dan kadar aspal dalam campuran. Nilai stabilitas (Gambar 5), agregat ex Lahat mempunyai mempunyai nilai yang lebih tinggi 
dibandingkan campuran lainnya, hal ini disebabkan agregat ex Lahat mempunyai nilai abrasi yang lebih tinggi. Stabilitas agregat ex Lahat Laston Aspal PEN 60/70 lebih tinggi daripada Laston AsButon Pracampuran, namun sebaliknya pada agregat ex Linggau dan ex Merak.

Campuran yang memiliki angka kelelehan rendah dengan stabilitas tinggi cenderung menjadi kaku dan getas. Sedangkan campuran yang memiliki angka kelelehan tinggi dan stabilitas rendah cenderung plastis dan mudah berubah bentuk seperti gelombang (washboarding) dan alur (rutting) apabila mendapat beban lalu lintas oleh sebab itu spesikasi membatasi nilai flow yaitu 2-4 mm untuk Laston aspal PEN 60/70 sedangkan nilai flow untuk Laston AsButon Pracampuran 2-4,5 mm. Nilai flow yang rendah akan mengakibatkan campuran menjadi kaku sehingga lapis perkerasan menjadi mudah retak saat dibebani.

Berdasarkan nilai stabilitas (Gambar 5) dan nilai flow (Gambar 6), dapat disimpulkan bahwa Laston AsButon Pracampuran mempunyai ketahanan rutting dan fleksibilitas yang baik, hal ini mendukung penelitian Anwar Yamin (2014).

\section{KESIMPULAN}

Dari hasil penelitian yang dilakukan terhadap Laston AsButon Pracampuran dan Laston aspal PEN 60/70 didapat simpulan bahwa:

a. Sifat fisik AsButon pracampuran mempunyai titik lembek serta titik nyala dan titik bakar lebih tinggi dibandingkan aspal PEN 60/70.

b. Laston AsButon pracampuran lebih ekonomis karena mempunyai nilai KAO lebih rendah dibandingkan
Laston PEN 60/70. Dengan nilai KAO lebih rendah Laston AsButon pracampuran juga mempunyai nilai stabilitas, durabilitas, fleksibilitas dan ketahanan rutting yang sama dengan Laston PEN 60/70 serta memenuhi Spesifikasi Teknis Campuran Beraspal dengan Asbuton.

\section{DAFTAR PUSTAKA}

[1] Affandy F. 2012. The performance of bituminous mixes using Indonesia natural asphalt. 25th ARRB Conference Perth, Western Australia.

[2] Andri danArief Setiawan. 2015. Pemanfaatan Kapur Tondo Sebagai Filler Pada Campuran Beton Lapis Aus. The 18 th, fstpt tnternational symposium, Unila, Bandar Lampung, August, 28.

[3] Anwar Yamin, H. R., Willy Pravianto dan Hikma Dewita. 2014. Asbuton Pracampur Antara Harapan dan Kenyataan. Poli Rekayasa. Volume 10, Nomor 1, Oktober, hal 31-41.

[4] Bina Marga. 2010. Perkerasan Aspal, Spesifikasi Umum Divisi VI Revisi 3. Jakarta.

[5] Bayu Aditya Pratama dan Miftahul Fauziah. 2017. Perbandingan Kinerja Campuran HOT Rolled Asphalt (HRA) Dengan Bahan Ikat Aspal PEN 60/70 Dan Aspal Retona Blend 55 Dengan Variasi Durasi Rendaman Air Laut. Jurnal Teknisia, Volume XXII, No. 1, Mei, hal 324-333.

[6] Eva Wahyu Indriyati. 2017. Kajian Perbandingan Penggunaan Aspal Modifikasi AsButon Dan Asphalt Rubber (AR) Untuk Infrastruktur Jalan. Jurnal teknik Sipil, Volume 14, No. 2, April, hal 94 -100.

[7] Gumay, A. 2014. Analisa Perbandingan Penggunaan Aspal Retona dan Aspal Pertamina dalam 
Perkerasan AC-WC. Tapak, vol.3, No.2, hal 120-126.

[8] Kementerian Pekerjaan Umum. 2013. Pedoman Spesifikasi Teknis Campuran Beraspal dengan Asbuton, Jakarta.

[9] Muhammad Yacob dan Wesli. 2017. Pengaruh Kadar Filler Abu Batu Kapur Dan Abu Tempurung Kelapa Terhadap Karakteristik Marshall Pada Campuran Aspal Beton AC-BC. Teras Jurnal, Vol.7, No.1, Maret, hal 213-222.
[10] Nyoman Suaryana, Neni Kusnianti. 2016. Karakteristik Campuran Hangat AsButon Dengan Bahan Tambah Berbasis Parafin. Jurnal Jalan-Jembatan, Volume 33, No. 2, Juli-Desember, hal 80-91.

[11]PT. Nala Anggada Perkasa. 2014. Asphalt Concrete Industry Bitumen Proceesing \& Trading Technical Assistance. ptnalaanggada@gmail.com.7 Nov.

Tabel 1. Sifat Fisik Aspal PEN 60-70 dan AsButon Pre-blended

\begin{tabular}{|c|c|c|c|c|c|}
\hline \multirow[b]{2}{*}{ Jenis Pengujian } & \multirow[b]{2}{*}{$\begin{array}{c}\text { Metode } \\
\text { Pengujian }\end{array}$} & \multicolumn{2}{|c|}{ Hasil Pengujian } & \multicolumn{2}{|c|}{ Spesifikasi } \\
\hline & & $\begin{array}{c}\text { Asbuton } \\
\text { Pra } \\
\text { campuran }\end{array}$ & $\begin{array}{c}\text { Aspal } \\
\text { PEN } \\
60 / 70\end{array}$ & $\begin{array}{c}\text { Asbuton } \\
\text { Pra }^{1} \text { ) } \\
\text { Campuran }\end{array}$ & $\begin{array}{c}\text { Aspal } \\
\text { PEN 2) } \\
60 / 70\end{array}$ \\
\hline 1. Penetrasi Pada $25^{\circ} \mathrm{C}(\mathrm{mm})$ & SNI 06-2456-1991 & 60,66 & 63,83 & $\geq 50$ & $60-70$ \\
\hline 2. Titik Lembek $\left({ }^{\circ} \mathrm{C}\right)$ & SNI 06-2434-1991 & 53,5 & 48,5 & $\geq 53$ & $\geq 48$ \\
\hline 3. Daktilitas Pada $25^{\circ} \mathrm{C}(\mathrm{cm})$ & SNI 06-2432-1991 & $\geq 100$ & $\geq 100$ & $\geq 100$ & $\geq 100$ \\
\hline 4. Titik Nyala $\left({ }^{\circ} \mathrm{C}\right)$ & SNI 06-2433-1991 & 335 & 280,1 & $\geq 232$ & $\geq 232$ \\
\hline 5. Kelarutan Dlm Toluene (\%) & RSNI M -04-2004 & 97,7 & 99,8 & $\geq 90$ & $\geq 99$ \\
\hline 6. Berat Jenis & SNI 06-2441-1991 & 1,045 & 1,02 & $\geq 1,0$ & $\geq 1,0$ \\
\hline 7. Berat yang Hilang (\%) & SNI 06-6441-1991 & 0,57 & 0,17 & $\leq 0,8$ & $\leq 0,8$ \\
\hline 8. Penetrasi TFOT & SNI 06-2456-1991 & 61,9 & 62,8 & $\geq 54$ & $\geq 54$ \\
\hline 9. Daktilitas TFOT (cm) & SNI 06-2432-1991 & $\geq 100$ & $\geq 100$ & $\geq 50$ & $\geq 100$ \\
\hline
\end{tabular}

Tabel 2. Sifat Fisik Agregat Kasar

\begin{tabular}{|c|c|c|c|c|c|}
\hline \multirow{2}{*}{ Pengujian } & \multirow{2}{*}{ Standar } & \multicolumn{3}{|c|}{ Hasil Pengujian (\%) } & \multirow{2}{*}{ Spesifikasi } \\
\hline & & Lahat & Linggau & Merak & \\
\hline $\begin{array}{l}\text { Kekekalan bentuk agregat } \\
\text { terhadap Magnesium Sulfat }\end{array}$ & SNI 3470:2008 & 0,69 & 2,01 & 4,13 & Maks. 18\% \\
\hline $\begin{array}{l}\text { Abrasi dengan mesin Los } \\
\text { Angles ( } 500 \text { putaran) }\end{array}$ & SNI 2417:2008 & 12,67 & 23,89 & 33,44 & Maks. 40\% \\
\hline $\begin{array}{l}\text { Kelekatan Agregat terhadap } \\
\text { aspal }\end{array}$ & SNI 2439:2011 & 99 & 99 & 99 & Min. 95\% \\
\hline $\begin{array}{l}\text { Butiran Pecah Pada agregat } \\
\text { kasar }\end{array}$ & SNI 7619:2012 & $97 / 95$ & $98 / 96$ & $97 / 94$ & $95 / 90^{*}$ \\
\hline Partikel Pipih dan Lonjong & $\begin{array}{c}\text { ASTM D4791 } \\
\text { Perbandingan 1: } 5\end{array}$ & 0,47 & 1,32 & 3,26 & Maks. $10 \%$ \\
\hline $\begin{array}{l}\text { Material lolos ayakan } \\
\text { No. } 200\end{array}$ & SNI 03-4142-1996 & 0,33 & 0,67 & 1,1 & Maks 2\% \\
\hline
\end{tabular}


Tabel 3. Sifat Fisik Agregat Halus

\begin{tabular}{|c|c|c|c|c|c|}
\hline \multirow{2}{*}{ Pengujian } & \multirow{2}{*}{ Standar } & \multicolumn{3}{|c|}{ Hasil Pengujian } & \multirow{2}{*}{ Spesifikasi } \\
\hline & & Lahat & Linggau & Merak & \\
\hline Nilai Setara Pasir & SNI 03-4428-1997 & $80 \%$ & $75 \%$ & $70 \%$ & Min 60\% \\
\hline $\begin{array}{l}\text { Angularitas dengan uji rongga } \\
\text { udara }\end{array}$ & SNI 03-6877-2002 & 53,95 & 52,04 & 52,29 & Min 45 \\
\hline $\begin{array}{l}\text { Gumpalan Lempung dan butiran- } \\
\text { butiran mudah pecah }\end{array}$ & SNI 03-4141: 1996 & 0,5 & 0,8 & 2,0 & Maks. 1\% \\
\hline Material Lolos Ayakan No.200 & $\begin{array}{c}\text { SNI ASTM C117: } \\
2012\end{array}$ & 0,4 & 0,75 & 1,8 & Maks. $10 \%$ \\
\hline
\end{tabular}

Tabel 4. Nilai Karakteristik Laston AC-BC dengan KAO

\begin{tabular}{|c|c|c|c|c|c|c|c|c|c|}
\hline \multirow{2}{*}{\multicolumn{4}{|c|}{ Sifat-Sifat Campuran }} & \multicolumn{2}{|c|}{ Ex. Lahat } & \multicolumn{2}{|c|}{ Ex. Linggau } & \multicolumn{2}{|c|}{ Ex. Merak } \\
\hline & & & & $\begin{array}{l}\text { Asbuton } \\
\text { Pra } \\
\text { camp. }\end{array}$ & $\begin{array}{l}\text { Aspal } \\
\text { PEN } \\
60 / 70\end{array}$ & $\begin{array}{l}\text { Asbuton } \\
\text { Pra } \\
\text { camp. }\end{array}$ & $\begin{array}{l}\text { Aspal } \\
\text { PEN } \\
60 / 70\end{array}$ & $\begin{array}{l}\text { Asbuton } \\
\text { Pra } \\
\text { camp. }\end{array}$ & $\begin{array}{l}\text { Aspal } \\
\text { PEN } \\
60 / 70\end{array}$ \\
\hline \multicolumn{4}{|c|}{ KAO (\%) } & 5,1 & 5,4 & 5,4 & 5,6 & 5,80 & 6,00 \\
\hline \multicolumn{2}{|c|}{ Persyaratan } & Asb & Asp & & & & & & \\
\hline VIM (\%) & $\begin{array}{l}\text { Min } \\
\text { Maks }\end{array}$ & $\begin{array}{l}3 \\
5\end{array}$ & $\begin{array}{l}3 \\
5\end{array}$ & 4,7 & 4,0 & 4,8 & 4,6 & 4,5 & 4,8 \\
\hline (VMA) (\%) & Min & 14 & 14 & 14,1 & 14,1 & 14,1 & 14,5 & 14,5 & 15,1 \\
\hline (VFA) (\%) & Min & 63 & 65 & 64 & 67 & 64 & 66 & 66 & 67 \\
\hline $\begin{array}{c}\text { Stabilitas } \\
\text { Marshall (kg) }\end{array}$ & Min & 1000 & 800 & 1405 & 1490 & 1270 & 1120 & 1315 & 1215 \\
\hline $\begin{array}{l}\text { Pelelehan/ } \\
\text { flow (mm) } \\
\text { Stabilitas }\end{array}$ & $\begin{array}{l}\text { Min } \\
\text { Maks }\end{array}$ & $\begin{array}{c}2 \\
4,5\end{array}$ & $\begin{array}{l}2 \\
4\end{array}$ & 3,7 & 3,9 & 3,9 & 3,9 & 3,9 & 3,9 \\
\hline $\begin{array}{c}\text { Marshall sisa } \\
\text { (\%) }\end{array}$ & Min & 90 & 90 & 98,60 & 98,48 & 96,99 & 94,75 & 92,78 & 93,49 \\
\hline $\begin{array}{c}\text { VIM Refusal } \\
(\%)\end{array}$ & Min & 2 & 2 & 3,5 & 3,5 & 4,5 & 4,3 & 4,2 & 4,6 \\
\hline
\end{tabular}

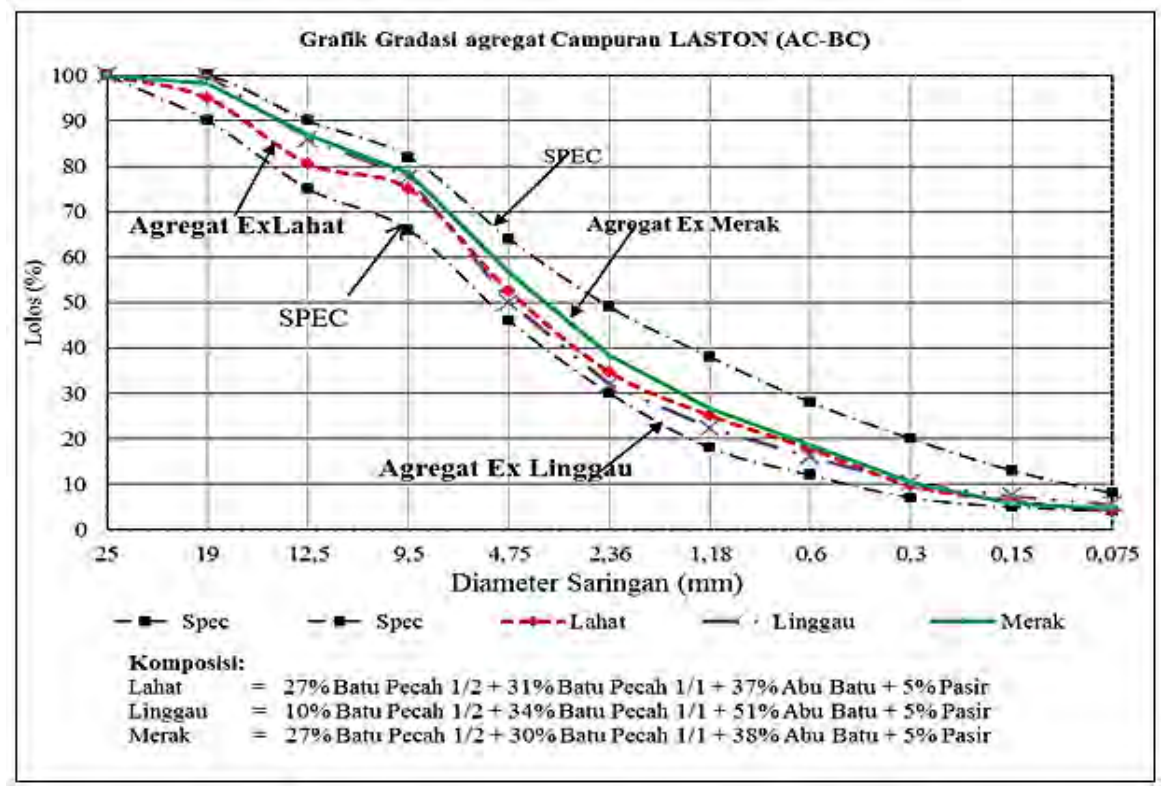

Gambar 1. Gradasi Campuran Agregat LASTON (AC-BC) 


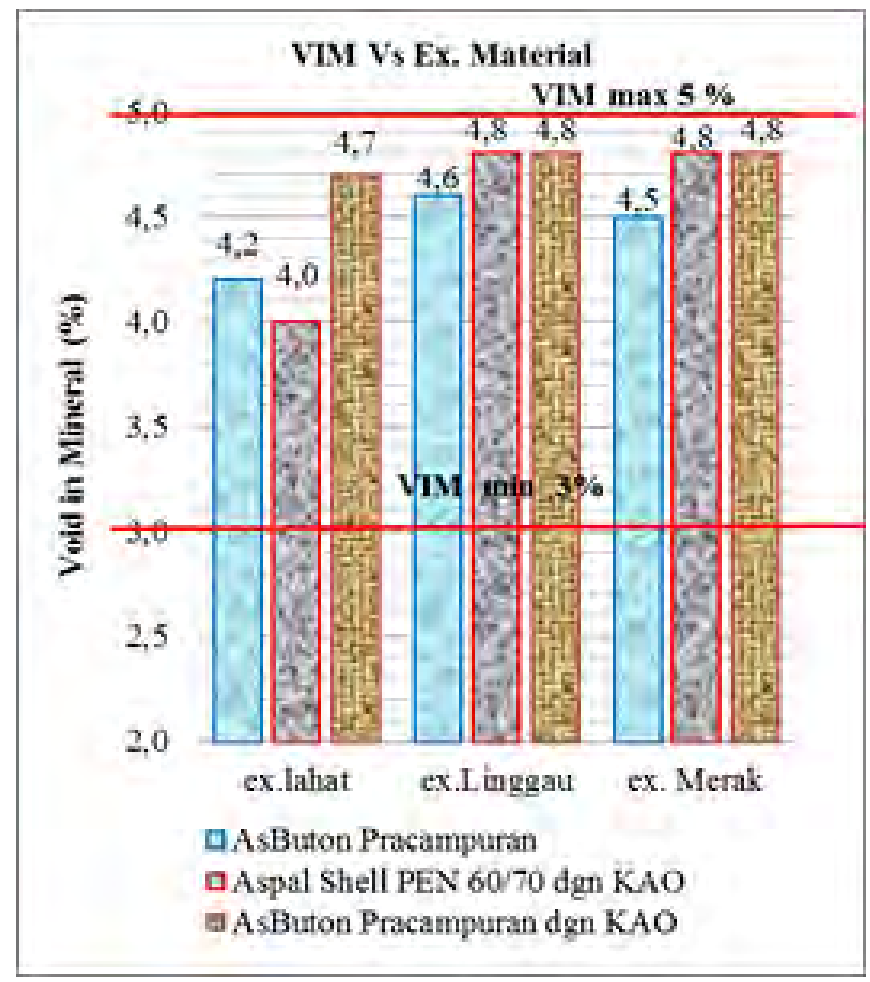

Gambar 2. Void in Mineral

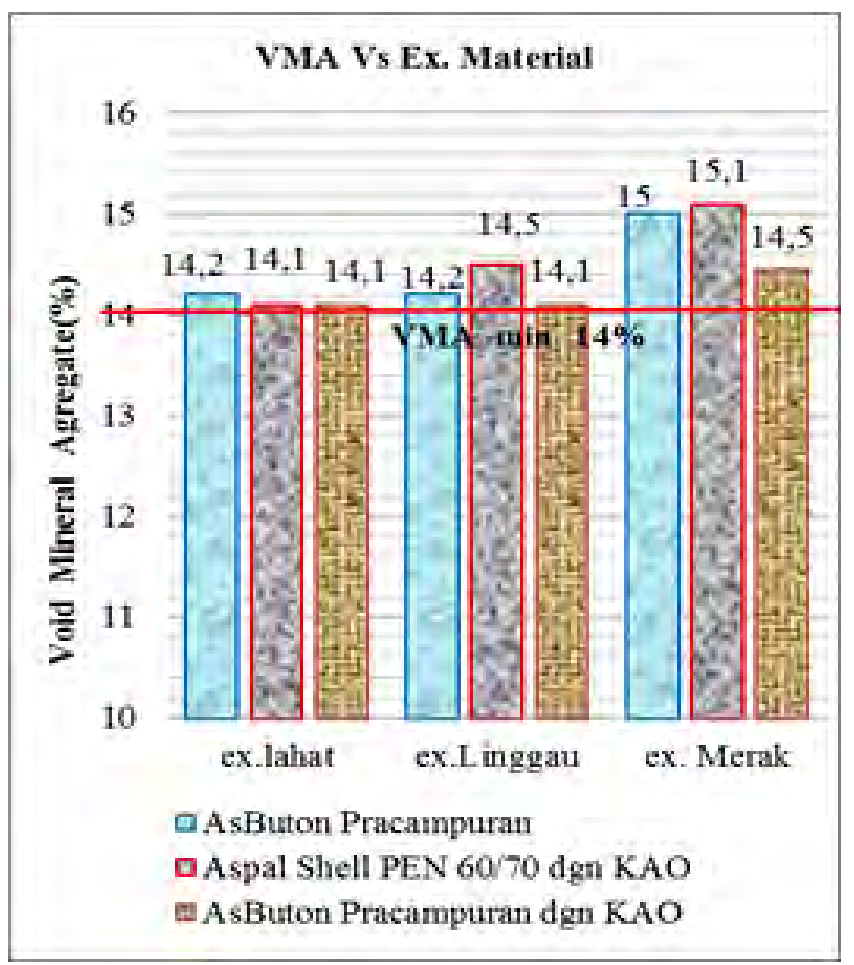

Gambar 3. Void Mineral Agregat 
Sumiati, Mahmuda dan Puryanto, Keunggulan Asbuton Pracampuran...

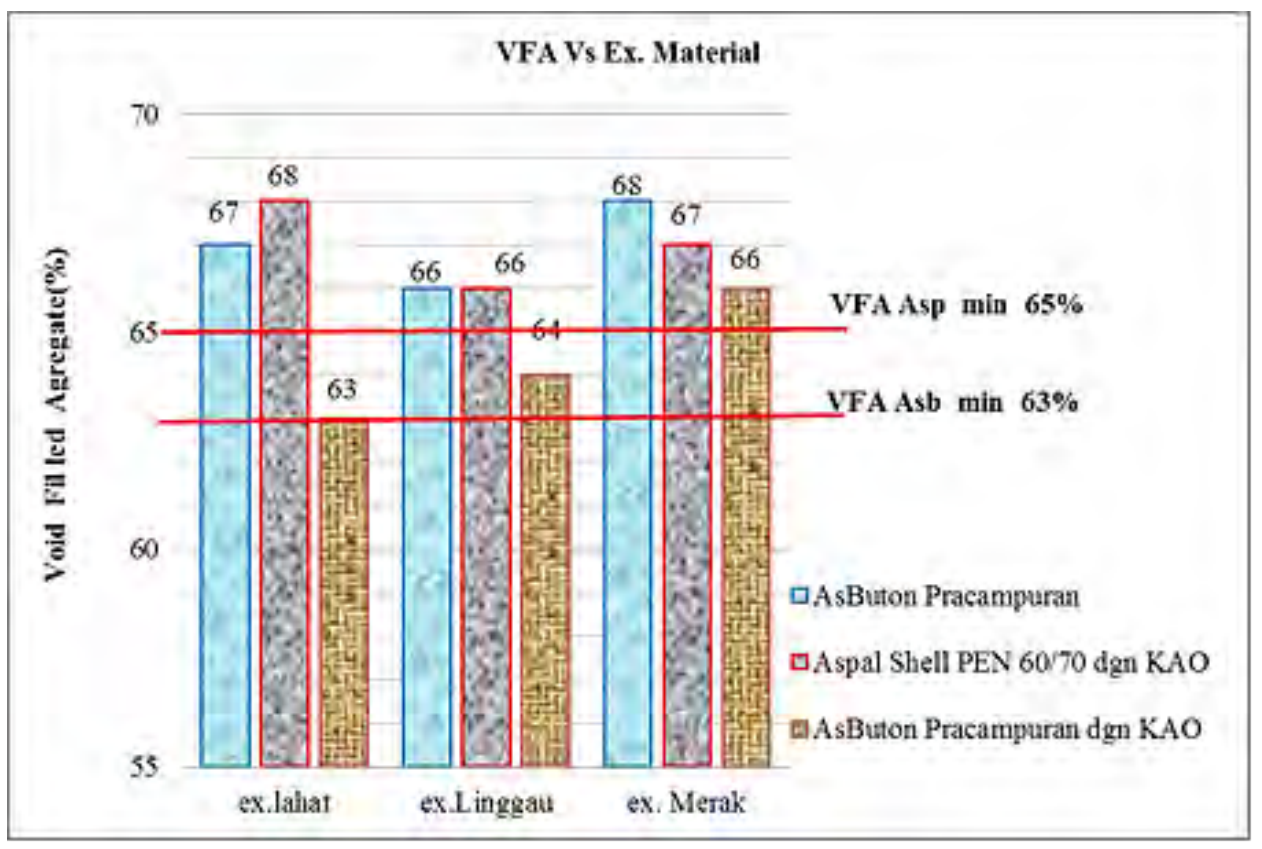

Gambar 4. Void Filled Aggregate

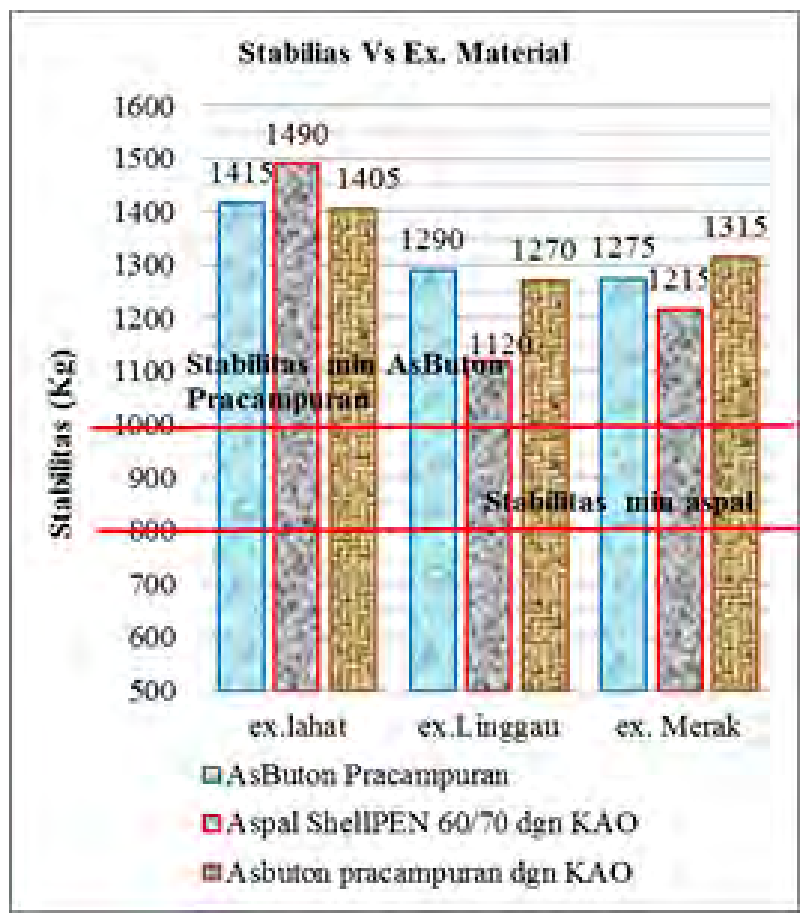

Gambar 5. Stabilitas 
POLITEKNOLOGI VOL. 18 NO. 1 JANUARI 2019

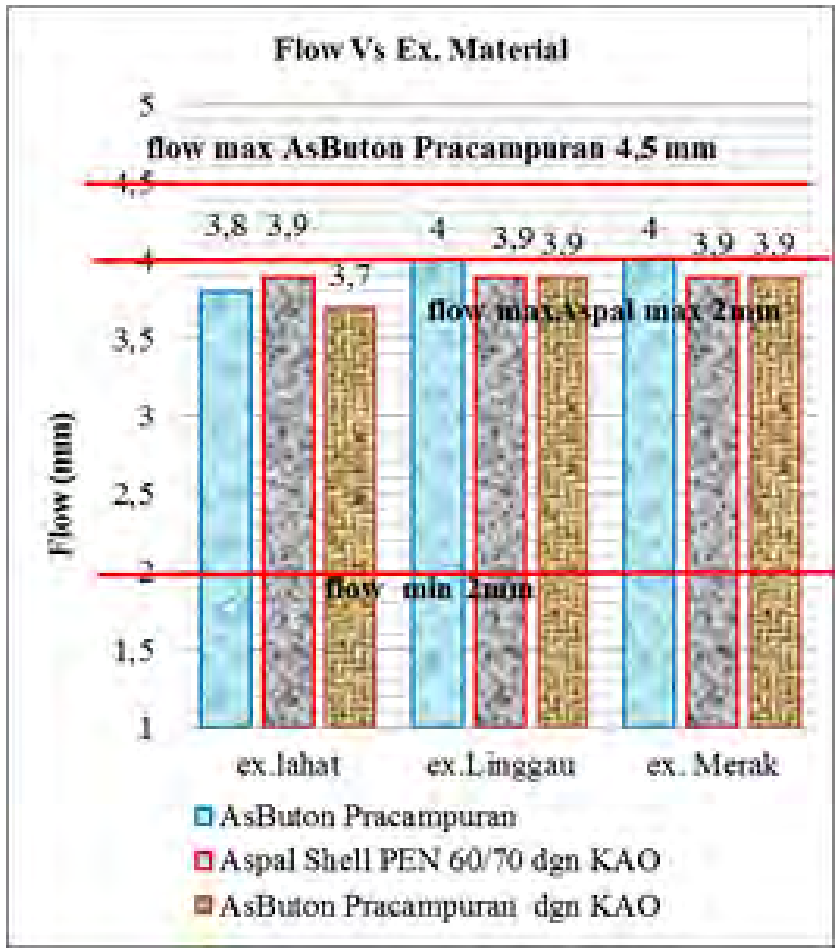

Gambar 6. Flow 
Sumiati, Mahmuda dan Puryanto, Keunggulan Asbuton Pracampuran... 